\title{
Cervical Cancer Recurrence, Prognosis, And Related Risk Factors For Patients With Cervical Cancer: A Long- Term Prospective Cohort Study
}

Jina Li

Central South University

Gaoming Liu

Hunan Cancer Hospital \& The Affiliated Cancer Hospital of Xiangya School of Medicine, Central South University

Jiayou Luo

Central South University

Shipeng Yan

Hunan Cancer Hospital \& The Affiliated Cancer Hospital of Xiangya School of Medicine, Central South University

Ping Ye

Central South University

Jie Wang

Central South University

Miyang Luo ( $\nabla$ miyangluo@csu.edu.cn )

Central South University

\section{Research Article}

Keywords: Uterine Cervical Neoplasms, Neoplasm Recurrence, Risk Factors, Cohort Studies, Prognosis.

Posted Date: March 3rd, 2022

DOI: https://doi.org/10.21203/rs.3.rs-1380445/v1

License: (c) (i) This work is licensed under a Creative Commons Attribution 4.0 International License. Read Full License 


\section{Abstract}

This study aims to explore the recurrence rate and prognosis for patients with cervical cancer after the first treatment and the related risk factors. We performed a prospective cohort of cervical cancer patients enrolled in a cancer specialist hospital in Hunan Province, China from January 1992 to December 2005 and followed up until December 2010. Kaplan-Meier survival analysis was used to estimate cumulative recurrence rate, and Cox proportional hazard model was utilized to identify risk factors associated with recurrence. A total of 4358 patients were enrolled with a median follow-up of 7.4 years (range 5-19 years), and 372 (8.5\%) patients had cancer recurrence. The cumulative recurrence rate showed a rapid increase from $3.8 \%$ in the first year to $8.0 \%$ in the fifth year, and the recurrence rate remained relatively stable afterward reaching $9.7 \%$ and $10.8 \%$ at the $10^{\text {th }}$ and the $15^{\text {th }}$ year respectively. The median time to recurrence was 15.5 months with an IQR of 5.5 to 40.0 months. The Cox regression showed that age, age of menarche, miscarriage, clinical stage, and treatment plan were significantly associated with cervical cancer recurrence after adjustment for confounders. Patients with recurrence showed a significantly lower survival probability than those without recurrence. This study depicted the long-term recurrence rate and survival after recurrence for patients with cervical cancer after the first treatment, and reported time to recurrence and risk factors related to recurrence. These findings may provide important evidence for designing targeted interventions for the treatment of cervical cancer.

\section{Introduction}

Cervical cancer is the most common malignant tumor in the female reproductive system globally, which has been seriously threatening women's lives. ${ }^{1}$ According to the 2020 Global Cancer Statistics Report, there were about 604,127 new cases of cervical cancer and 341,831 relevant deaths worldwide each year, accounting for $6.5 \%$ and $7.7 \%$ of the total number of cancer incidences and deaths in women, respectively. ${ }^{2}$ Although there are standardized treatment methods for cervical cancer, patients after treatment often face the dilemma of recurrence. ${ }^{3}$ Cervical cancer recurrence is the main reason for treatment failure. Once the recurrence happens, the patient is left with very limited treatment options and a poor prognosis in general. ${ }^{4}$ It is estimated that the 5 -year survival rate for cervical cancer patients with recurrence was only about $10.0 \% .^{5}$ Thus, the prevention of cervical cancer recurrence has become a huge challenge in clinical practice.

Reducing the recurrence of cervical cancer requires an improved understanding of the actual recurrence rate, time to recurrence, and its related risk factors. Previous studies reported that the recurrence rate of cervical cancer varied a lot in different populations (approximately 6.4-21.1\%). ${ }^{6-10}$ To our knowledge, only a few studies focused on the pattern of recurrence rate and survival after recurrence in China. ${ }^{11-13}$ However, most of these studies had a small sample size and a short period of observation, or were based on data from clinical trials which may limit its generalizability. In addition, most of the studies lacked in-depth research on the recurrence time, ${ }^{14,15}$ such as the analysis of the recurrence time for patients with different age groups, age of menarche, parity, clinical stages, and treatment plans. Moreover, despite that previous studies have reported several risk factors of cervical cancer recurrence and prognosis, including patient's age, ethnicity, pathological type, clinical stage, lymph node metastasis, tumor size, and treatment received, ${ }^{16,17}$ there is still controversy about certain risk factors, for instance, some studies reported inconsistent results for age, pathological type, and differentiation. ${ }^{6,18,19}$

This study aims to explore the long-term recurrence rate, time to recurrence, and survival after recurrence for patients with cervical cancer after the first treatment and identify the potential risk factors, using a large 
prospective cohort, which may provide a scientific basis for the effective prevention and treatment of cervical cancer recurrence.

\section{Results}

\section{Characteristics of the Study Population}

From January 1992 to December 2005, a total of 4374 subjects diagnosed with cervical cancer and completed the initial treatment in the study hospital were enrolled in the study. After excluding 16 subjects who were lost to follow-up, we included 4358 subjects with mean age of 46.5 years in the final analyses. The mean follow-up duration was 7.4 years with range from 5 to 19 years.

In this study, $46.6 \%$ of subjects were in clinical stage $\nabla, 40.8 \%$ of subjects were in clinical stage $\nabla$, and $12.6 \%$ of subjects were in clinical stage $\nabla$ and IV (Table 1). In addition, 3864 (92.2\%) subjects had squamous cell carcinoma, $261(6.2 \%)$ subjects had adenocarcinoma, and 68 (1.6\%) subjects had other types of cervical cancer. In terms of level of differentiation, 479 (12.0\%) subjects were well-differentiated, 3332 (83.7\%) subjects were moderately differentiated, 172 (4.3\%) subjects were poorly differentiated/ undifferentiated. Around half of the subjects conducted surgical treatment, and radical hysterectomy was conducted for most subjects. Around $90 \%$ of subjects conducted radiotherapy, and $42.6 \%$ of subjects conducted adjuvant radiotherapy alone with surgery.

Chemotherapy was conducted for $28.4 \%$ of subjects, and $12.1 \%$ of subjects conducted concurrent chemotherapy with radiotherapy. 
Table 1

Patient characteristics

\begin{tabular}{|c|c|c|c|c|}
\hline & Overall & $\begin{array}{l}\text { Recurrence: } \\
\text { No }\end{array}$ & $\begin{array}{l}\text { Recurrence: } \\
\text { Yes }\end{array}$ & $\begin{array}{l}p- \\
\text { value }\end{array}$ \\
\hline $\mathrm{N}$ & 4358 & 3986 & 372 & \\
\hline Age (years, mean (SD)) a & $\begin{array}{l}46.46 \\
(10.25)\end{array}$ & $\begin{array}{l}46.57 \\
(10.30)\end{array}$ & $45.34(9.67)$ & 0.028 \\
\hline Age group (years, \%) ${ }^{a}$ & & & & 0.003 \\
\hline$<55$ & $3414(78.4)$ & 3099 (77.8) & $315(84.7)$ & \\
\hline$\geq 55$ & $940(21.6)$ & $883(22.2)$ & $57(15.3)$ & \\
\hline Age of menarche (years, $\%)^{b}$ & & & & $\begin{array}{l}< \\
0.001\end{array}$ \\
\hline$\leq 15$ & $2589(61.0)$ & $2333(60.2)$ & $256(69.9)$ & \\
\hline$>15$ & $1652(39.0)$ & $1542(39.8)$ & $110(30.1)$ & \\
\hline Gravidity (times, \%) & & & & 0.333 \\
\hline $0-2$ & $911(20.9)$ & $841(21.1)$ & $70(18.8)$ & \\
\hline$\geq 3$ & 3447 (79.1) & 3145 (78.9) & $302(81.2)$ & \\
\hline Parity (times, \%) & & & & 0.015 \\
\hline $0-2$ & $2040(46.8)$ & $1843(46.2)$ & $197(53.0)$ & \\
\hline$\geq 3$ & $2318(53.2)$ & $2143(53.8)$ & $175(47.0)$ & \\
\hline Miscarriage (times, \%) & & & & 0.003 \\
\hline 0 & $1824(41.9)$ & $1694(42.5)$ & $130(34.9)$ & \\
\hline $1-2$ & $1806(41.4)$ & $1646(41.3)$ & $160(43.0)$ & \\
\hline$\geq 3$ & $728(16.7)$ & $646(16.2)$ & $82(22.0)$ & \\
\hline Age of menopause (years, \%) & & & & 0.372 \\
\hline No & $2894(66.4)$ & $2638(66.2)$ & $256(68.8)$ & \\
\hline$<45$ & $251(5.8)$ & $226(5.7)$ & $25(6.7)$ & \\
\hline $45-55$ & $1186(27.2)$ & $1098(27.5)$ & $88(23.7)$ & \\
\hline$>55$ & $27(0.6)$ & $24(0.6)$ & $3(0.8)$ & \\
\hline $\begin{array}{l}\text { Duration of discomfort before diagnosis (months, } \\
\% \text { ) }\end{array}$ & & & & 0.354 \\
\hline
\end{tabular}

CRT, concurrent chemotherapy and radiotherapy

a 4 missings; ${ }^{b} 117$ missings; ${ }^{c} 204$ missings; ${ }^{d} 165$ missings. ${ }^{e} 7$ missings; ${ }^{f}$ based on biopsy after surgery. 


\begin{tabular}{|c|c|c|c|c|}
\hline & Overall & $\begin{array}{l}\text { Recurrence: } \\
\text { No }\end{array}$ & $\begin{array}{l}\text { Recurrence: } \\
\text { Yes }\end{array}$ & $\begin{array}{l}p- \\
\text { value }\end{array}$ \\
\hline$<3$ & $1951(44.8)$ & $1797(45.1)$ & $154(41.4)$ & \\
\hline $3-12$ & $2006(46.0)$ & $1822(45.7)$ & $184(49.5)$ & \\
\hline$>12$ & $401(9.2)$ & $367(9.2)$ & $34(9.1)$ & \\
\hline Clinical stage $(\%)^{\mathrm{C}}$ & & & & $\begin{array}{l}< \\
0.001\end{array}$ \\
\hline la & $57(1.4)$ & $54(1.4)$ & $3(0.9)$ & \\
\hline lb1 & $1371(33.0)$ & $1281(33.6)$ & $90(25.9)$ & \\
\hline lb2 & $508(12.2)$ & $463(12.2)$ & $45(13.0)$ & \\
\hline Ila & $198(4.8)$ & $163(4.3)$ & $35(10.1)$ & \\
\hline Ilb & $1496(36.0)$ & $1373(36.1)$ & $123(35.4)$ & \\
\hline Illa & $38(0.9)$ & $32(0.8)$ & $6(1.7)$ & \\
\hline IIIb & $473(11.4)$ & $430(11.3)$ & $43(12.4)$ & \\
\hline IVa & $8(0.2)$ & $7(0.2)$ & $1(0.3)$ & \\
\hline $\mathrm{IVb}$ & $5(0.1)$ & $4(0.1)$ & $1(0.3)$ & \\
\hline Pathological type (\%) ${ }^{d}$ & & & & 0.383 \\
\hline Squamous cell carcinoma & 3864 (92.2) & $3530(92.2)$ & $334(91.8)$ & \\
\hline Adenocarcinoma & $261(6.2)$ & $240(6.3)$ & $21(5.8)$ & \\
\hline Others & $68(1.6)$ & $59(1.5)$ & $9(2.5)$ & \\
\hline Level of differentiation (\%) & & & & 0.507 \\
\hline Well & $479(12.0)$ & $440(12.1)$ & $39(11.2)$ & \\
\hline Moderate & 3332 (83.7) & 3041 (83.7) & $291(83.4)$ & \\
\hline Poor/undifferentiated & $172(4.3)$ & $153(4.2)$ & $19(5.4)$ & \\
\hline Treatment plan (\%) $\mathrm{e}$ & & & & $\begin{array}{l}< \\
0.001\end{array}$ \\
\hline Surgery only & $262(6.0)$ & $253(6.4)$ & $9(2.4)$ & \\
\hline Surgery + radiotherapy & $1308(30.1)$ & $1220(30.7)$ & $88(23.7)$ & \\
\hline Surgery + chemotherapy & $119(2.7)$ & $99(2.5)$ & $20(5.4)$ & \\
\hline Surgery + CRT & 547 (12.6) & $486(12.2)$ & $61(16.4)$ & \\
\hline
\end{tabular}

CRT, concurrent chemotherapy and radiotherapy

a 4 missings; ${ }^{b} 117$ missings; ${ }^{c} 204$ missings; ${ }^{d} 165$ missings. ${ }^{e} 7$ missings; ${ }^{f}$ based on biopsy after surgery. 


\begin{tabular}{|c|c|c|c|c|}
\hline & Overall & $\begin{array}{l}\text { Recurrence: } \\
\text { No }\end{array}$ & $\begin{array}{l}\text { Recurrence: } \\
\text { Yes }\end{array}$ & $\begin{array}{l}p- \\
\text { value }\end{array}$ \\
\hline Radiotherapy only & $1545(35.5)$ & $1432(36.0)$ & $113(30.4)$ & \\
\hline CRT & $526(12.1)$ & $456(11.5)$ & 70 (18.8) & \\
\hline Chemotherapy only & $44(1.0)$ & $33(0.8)$ & $11(3.0)$ & \\
\hline Surgery methods $(\%)^{f}$ & & & & 0.143 \\
\hline No & $2122(51.0)$ & $1928(50.6)$ & $194(55.1)$ & \\
\hline Radical trachelectomy & $93(2.2)$ & $83(2.2)$ & $10(2.8)$ & \\
\hline Simple hysterectomy & $72(1.7)$ & $70(1.8)$ & $2(0.6)$ & \\
\hline Radical hysterectomy & $1752(42.1)$ & $1613(42.3)$ & $139(39.5)$ & \\
\hline Others & $125(3.0)$ & $118(3.1)$ & $7(2.0)$ & \\
\hline Lymph node metastasis (\%) & & & & 0.008 \\
\hline No & $1804(85.2)$ & 1664 (85.9) & $140(78.2)$ & \\
\hline Yes & $313(14.8)$ & $274(14.1)$ & $39(21.8)$ & \\
\hline Radiotherapy (\%) & & & & 0.568 \\
\hline No & $432(9.9)$ & $392(9.8)$ & $40(10.8)$ & \\
\hline Adjuvant & $1855(42.6)$ & $1706(42.8)$ & $149(40.1)$ & \\
\hline Initial & $2071(47.5)$ & $1888(47.4)$ & $183(49.2)$ & \\
\hline Chemotherapy (\%) & & & & $\begin{array}{l}< \\
0.001\end{array}$ \\
\hline No & $3122(71.6)$ & $2912(73.1)$ & $210(56.5)$ & \\
\hline Adjuvant & $666(15.3)$ & $585(14.7)$ & $81(21.8)$ & \\
\hline Concurrent & $526(12.1)$ & $456(11.4)$ & $70(18.8)$ & \\
\hline Initial & $44(1.0)$ & $33(0.8)$ & $11(3.0)$ & \\
\hline \multicolumn{5}{|c|}{ CRT, concurrent chemotherapy and radiotherapy } \\
\hline
\end{tabular}

A total of 372 subjects had a cancer relapse during the follow-up period. Subjects with recurrence had significantly younger age, younger age of menarche, lower parity, a greater number of miscarriages, and higher clinical stage, and they were more likely to have lymph node metastasis and chemotherapy. We also compared the patient characteristics for those aged 55 years and above and patients younger than 55 years old (Supplemental Table 1). We found that compared to the younger age group the proportion of patients with clinical stage II and above were significantly higher in the older age group, while the proportion of patients receiving surgical treatment was significantly lower in the older age group. 


\section{Cumulative Rate And Time To Recurrence}

The overall cumulative recurrence rate was $3.8 \%$ in the first year and increased to $5.1 \%$ in the second year, and $8.0 \%$ in the fifth year. The increasing trend slowed down afterward and remained relatively stable at around $10 \%$ after ten years (Fig. 1). The median time to recurrence for the 372 subjects during follow-up was 15.5 months (IQR $5.5,40.0)$ (Table 2). There were significant differences in the recurrence rate when stratified by age group, age of menarche, parity, miscarriage, clinical stage, treatment plan, lymph node metastasis, and chemotherapy method ( $P$ $<0.05$, Fig. 2), and the average time to recurrence was significantly shorter for subjects with younger age, younger age of menarche, lower parity, a greater number of miscarriages, higher clinical stage, lymph node metastasis, and treatment with chemotherapy, especially for those with initial chemotherapy. 
Table 2

Time to recurrence in the study population $(\mathrm{N}=372)$

\begin{tabular}{|c|c|c|c|c|}
\hline \multirow[t]{2}{*}{ Variables } & \multicolumn{4}{|c|}{ Recurrence Time (months) } \\
\hline & Median & IQR & & $p$-value ${ }^{a}$ \\
\hline Overall & 15.5 & 5.5 & 40.0 & \\
\hline Age group (years) & & & & 0.002 \\
\hline$<55$ & 14.3 & 5.4 & 38.1 & \\
\hline$\geq 55$ & 24.2 & 10.0 & 42.0 & \\
\hline Age of menarche (years) & & & & $<0.001$ \\
\hline$\leq 15$ & 14.1 & 5.0 & 39.6 & \\
\hline$>15$ & 19.0 & 7.0 & 40.0 & \\
\hline Parity (times) & & & & 0.006 \\
\hline $0-2$ & 14.0 & 5.3 & 33.4 & \\
\hline$\geq 3$ & 20.0 & 5.9 & 46.4 & \\
\hline Miscarriage (times) & & & & 0.002 \\
\hline 0 & 17.2 & 5.9 & 42.1 & \\
\hline $1-2$ & 15.8 & 5.4 & 39.6 & \\
\hline$\geq 3$ & 14.9 & 5.6 & 36.2 & \\
\hline Clinical stage & & & & 0.002 \\
\hline I & 23.9 & 7.9 & 45.7 & \\
\hline II & 15.8 & 5.8 & 41.6 & \\
\hline III/IV & 9.1 & 5.8 & 23.6 & \\
\hline Treatment plan & & & & $<0.001$ \\
\hline Surgery only & 28.6 & 24.5 & 40.0 & \\
\hline Surgery + radiotherapy & 24.9 & 6.5 & 46.7 & \\
\hline Surgery + chemotherapy & 21.1 & 11.1 & 29.9 & \\
\hline Surgery + CRT & 15.4 & 5.6 & 34.8 & \\
\hline Radiotherapy only & 13.2 & 5.9 & 50.4 & \\
\hline CRT & 11.0 & 5.6 & 30.5 & \\
\hline
\end{tabular}

CRT, concurrent chemotherapy and radiotherapy

a $\mathrm{p}$-value was estimated using Log rank test. 


\begin{tabular}{|c|c|c|c|c|}
\hline \multirow[t]{2}{*}{ Variables } & \multicolumn{4}{|c|}{ Recurrence Time (months) } \\
\hline & Median & IQR & & p-value \\
\hline Chemotherapy only & 1.0 & 1.0 & 6.1 & \\
\hline Lymph node metastasis & & & & $<0.001$ \\
\hline No & 23.9 & 8.9 & 45.7 & \\
\hline Yes & 11.0 & 4.0 & 34.0 & \\
\hline Chemotherapy & & & & $<0.001$ \\
\hline No & 20.8 & 5.9 & 46.8 & \\
\hline Adjuvant & 17.0 & 6.4 & 33.6 & \\
\hline Concurrent & 11.0 & 5.6 & 30.5 & \\
\hline Initial & 1.0 & 1.0 & 6.1 & \\
\hline \multicolumn{5}{|c|}{ CRT, concurrent chemotherapy and radiotherapy } \\
\hline
\end{tabular}

\section{Risk Factors For Recurrence}

We further analyzed the risk factors for cervical cancer recurrence by constructing Cox proportional hazard regression models (Table 3). We observed that age, age of menarche, miscarriage, clinical stage, treatment plan remained significant after adjustment for confounders. More specifically, the recurrence risk for subjects with three or more times of miscarriages was increased $58 \%$ compared to those without a history of miscarriages; the HR for subjects with clinical state II was $1.52(95 \% \mathrm{Cl} 1.07,2.16)$ and clinical stage III or IV was $1.84(95 \% \mathrm{Cl} 1.17,2.90)$ compared to those with stage $\mathrm{I}$. 
Table 3

Analyzing factors associated with cervical cancer recurrence using Cox regression models

\begin{tabular}{|c|c|c|c|c|c|c|}
\hline \multirow[t]{2}{*}{ Variables } & \multicolumn{2}{|c|}{ Unadjusted model } & \multicolumn{4}{|c|}{ Multivariate model } \\
\hline & $\mathrm{HR}$ & $95 \% \mathrm{Cl}$ & $p$-value & $\mathrm{HR}$ & $95 \% \mathrm{Cl}$ & $p$-value \\
\hline \multicolumn{7}{|l|}{ Age group (years) } \\
\hline$<55$ & Ref & - & - & Ref & - & - \\
\hline$\geq 55$ & 0.65 & $0.49,0.86$ & 0.002 & 0.63 & $0.45,0.89$ & 0.009 \\
\hline \multicolumn{7}{|l|}{ Age of menarche (years) } \\
\hline$\leq 15$ & Ref & - & - & Ref & - & - \\
\hline$>15$ & 0.65 & $0.52,0.81$ & $<0.001$ & 0.62 & $0.49,0.80$ & $<0.001$ \\
\hline \multicolumn{7}{|l|}{ Parity (times) } \\
\hline $0-2$ & Ref & - & - & Ref & - & \\
\hline$\geq 3$ & 0.75 & $0.61,0.92$ & 0.007 & 0.91 & $0.71,1.17$ & 0.470 \\
\hline \multicolumn{7}{|l|}{ Miscarriage (times) } \\
\hline 0 & Ref & - & - & Ref & - & - \\
\hline $1-2$ & 1.25 & $0.99,1.58$ & 0.056 & 1.18 & $0.91,1.51$ & 0.209 \\
\hline$\geq 3$ & 1.61 & $1.22,2.13$ & 0.001 & 1.58 & $1.17,2.14$ & 0.003 \\
\hline \multicolumn{7}{|l|}{ Clinical stage } \\
\hline I & Ref & - & - & Ref & - & - \\
\hline II & 1.37 & $1.09,1.72$ & 0.007 & 1.52 & $1.07,2.16$ & 0.021 \\
\hline III/IV & 1.59 & $1.15,2.19$ & 0.005 & 1.84 & $1.17,2.90$ & 0.008 \\
\hline \multicolumn{7}{|l|}{ Pathological type } \\
\hline Squamous cell carcinoma & Ref & - & - & Ref & - & - \\
\hline Adenocarcinoma & 0.98 & $0.63,1.53$ & 0.945 & 0.78 & $0.46,1.31$ & 0.344 \\
\hline Others & 1.68 & $0.87,3.26$ & 0.125 & 1.83 & $0.67,4.97$ & 0.236 \\
\hline \multicolumn{7}{|l|}{ Level of differentiation } \\
\hline Well & Ref & - & - & Ref & - & - \\
\hline Moderate & 1.09 & $0.78,1.53$ & 0.600 & 1.05 & $0.74,1.50$ & 0.782 \\
\hline Poor/undifferentiated & 1.49 & $0.86,2.58$ & 0.152 & 1.31 & $0.72,2.39$ & 0.377 \\
\hline \multicolumn{7}{|l|}{ Treatment plan } \\
\hline Surgery only & Ref & - & - & Ref & - & - \\
\hline
\end{tabular}

$\mathrm{HR}$, hazard ratio; $\mathrm{Cl}$, confidence intervals; CRT, concurrent chemotherapy and radiotherapy 


\begin{tabular}{|lcccccc|}
\hline Variables & Unadjusted model & \multicolumn{4}{c|}{ Multivariate model } \\
\hline Surgery + radiotherapy & 2.00 & $1.01,3.96$ & 0.048 & 1.58 & $0.64,3.91$ & 0.320 \\
\hline Surgery + chemotherapy & 5.62 & $2.56,12.35$ & $<0.001$ & 3.83 & $1.39,10.50$ & 0.009 \\
\hline Surgery + CRT & 3.64 & $1.81,7.33$ & $<0.001$ & 2.18 & $0.87,5.49$ & 0.098 \\
\hline Radiotherapy only & 2.26 & $1.14,4.45$ & 0.019 & 1.46 & $0.56,3.78$ & 0.439 \\
\hline CRT & 4.69 & $2.34,9.39$ & $<0.001$ & 2.51 & $0.96,6.58$ & 0.062 \\
\hline Chemotherapy only & 10.85 & $4.50,26.20$ & $<0.001$ & 4.60 & $1.35,15.65$ & 0.015 \\
\hline HR, hazard ratio; Cl, confidence intervals; CRT, concurrent chemotherapy and radiotherapy \\
\hline
\end{tabular}

We also compared the treatment plan by different clinical stages (Table 4). For patients in clinical stage I, surgery + radiotherapy was the most common treatment (60.3\%), and $19.8 \%$ of subjects conducted surgery plus CRT. For patients in clinical stage II and above, the majority of them conducted radiotherapy alone or CRT. The recurrence rate for each treatment differed by clinical stage, and the recurrence rate was higher for patients with stage II and above than patients with stage I regarding most treatment plans. We also summarized the changes in cervical cancer recurrence rate, survival rate, and treatment methods during follow-up (Supplementary Table 2). From 1992 to 2005 , the recurrence rate of cervical cancer increased from $3.8-13.8 \%$, and the cervical cancer survival rate increased from 58.4-79.5\%. In terms of the treatment plan, patients with radiotherapy only decreased from 72.4$11.5 \%$, while those with surgery + chemotherapy and surgery + CRT increased from $0.5-6.7 \%$ and $1.3-22.8 \%$, respectively. 
Table 4

Comparison of recurrence rate for different treatment plans by clinical stages

\section{Clinical stage}

\begin{tabular}{|c|c|c|c|c|c|c|c|c|}
\hline & Overall & $\begin{array}{l}\text { Recurrence } \\
\text { rate }(\%)\end{array}$ & $\mathrm{I}$ & $\begin{array}{l}\text { Recurrence } \\
\text { rate (\%) }\end{array}$ & II & $\begin{array}{l}\text { Recurrence } \\
\text { rate }(\%)\end{array}$ & III/IV & $\begin{array}{l}\text { Recurrence } \\
\text { rate }(\%)\end{array}$ \\
\hline$N$ & 4150 & & 1934 & & 1692 & & 524 & \\
\hline \multicolumn{9}{|l|}{$\begin{array}{l}\text { Treatment } \\
\text { plan (\%) }\end{array}$} \\
\hline Surgery only & $\begin{array}{l}262 \\
(6.0)\end{array}$ & $9(3.4)$ & $\begin{array}{l}157 \\
(8.1)\end{array}$ & $6(3.8)$ & $\begin{array}{l}9 \\
(0.5)\end{array}$ & $0(0.0)$ & $\begin{array}{l}1 \\
(0.2)\end{array}$ & $0(0.0)$ \\
\hline $\begin{array}{l}\text { Surgery + } \\
\text { radiotherapy }\end{array}$ & $\begin{array}{l}1308 \\
(30.1)\end{array}$ & $88(6.7)$ & $\begin{array}{l}1166 \\
(60.3)\end{array}$ & $76(6.5)$ & $\begin{array}{l}123 \\
(7.3)\end{array}$ & $12(9.8)$ & $\begin{array}{l}5 \\
(1.0)\end{array}$ & $0(0.0)$ \\
\hline $\begin{array}{l}\text { Surgery + } \\
\text { chemotherapy }\end{array}$ & $\begin{array}{l}119 \\
(2.7)\end{array}$ & $20(16.8)$ & $\begin{array}{l}79 \\
(4.1)\end{array}$ & $11(13.9)$ & $\begin{array}{l}24 \\
(1.4)\end{array}$ & $6(25.0)$ & $\begin{array}{l}7 \\
(1.3)\end{array}$ & $1(14.3)$ \\
\hline Surgery + CRT & $\begin{array}{l}547 \\
(12.6)\end{array}$ & $61(11.2)$ & $\begin{array}{l}383 \\
(19.8)\end{array}$ & $31(8.1)$ & $\begin{array}{l}146 \\
(8.6)\end{array}$ & $27(18.5)$ & $\begin{array}{l}9 \\
(1.7)\end{array}$ & $1(11.1)$ \\
\hline $\begin{array}{l}\text { Radiotherapy } \\
\text { only }\end{array}$ & $\begin{array}{l}1545 \\
(35.5)\end{array}$ & $113(7.3)$ & $\begin{array}{l}110 \\
(5.7)\end{array}$ & $13(11.8)$ & $\begin{array}{l}1065 \\
(62.9)\end{array}$ & $69(6.5)$ & $\begin{array}{l}341 \\
(65.1)\end{array}$ & $26(7.6)$ \\
\hline CRT & $\begin{array}{l}526 \\
(12.1)\end{array}$ & 70 (13.3) & $\begin{array}{l}34 \\
(1.8)\end{array}$ & $1(2.9)$ & $\begin{array}{l}309 \\
(18.3)\end{array}$ & $40(12.9)$ & $\begin{array}{l}151 \\
(28.8)\end{array}$ & $21(13.9)$ \\
\hline $\begin{array}{l}\text { Chemotherapy } \\
\text { only }\end{array}$ & $\begin{array}{l}44 \\
(1.0)\end{array}$ & $11(25.0)$ & $\begin{array}{l}5 \\
(0.2)\end{array}$ & $0(0.0)$ & $\begin{array}{l}16 \\
(0.9)\end{array}$ & $4(25.0)$ & $\begin{array}{l}10 \\
(1.9)\end{array}$ & $2(20.0)$ \\
\hline
\end{tabular}

\section{Survival After Recurrence}

The total survival time was plotted for subjects with and without cancer recurrence (Fig. 3). The one-year survival probability for those without cancer recurrence was $96.3 \%$, and the five-year survival probability was $79.5 \%$, and the survival probability dropped to $50.7 \%$ after 15 years of follow-up. The survival probability was significantly lower for those with cancer recurrence, which was $90.6 \%$ in the first year, $54.0 \%$ in the fifth year, $28.7 \%$ in the 10 th year, and only $15.4 \%$ in the 15 th year.

\section{Discussion}

In this study, we reported the longitudinal pattern of cumulative recurrence rate over 15 years for patients with cervical cancer after the first treatment. We found that the overall crude recurrence rate was $8.5 \%$, and the median time to recurrence was 15.5 months. Also, we found that the cumulative recurrence rate increased rapidly from $3.8 \%$ in the first year to $8.0 \%$ in the fifth year, and the increasing trend slowed down afterward where the rate was $9.7 \%$ at the 10 th year and $10.8 \%$ in the 15 th year. The recurrence rate reported in this study was consistent with a 
systematic review in 2009 which found that the recurrence rate for patients who completed primary therapy for cervical cancer ranged from $8.0-26 \%$, and median time to recurrence ranged from 7 to 36 months. ${ }^{10} \mathrm{~A}$ more recent cohort study from Denmark that enrolled a population of 1523 women with clinical stage I cervical cancer in 2005-2013 showed a recurrence rate of $6.4 \%$ after 5 years of follow-up. ${ }^{6}$ A study in China reported that rates of recurrence were $16.9 \%$ and $12.4 \%$ for 148 stage Ilb patients with radical hysterectomy and 290 stage Ilb patients with radical radiotherapy, respectively. ${ }^{12}$ The variation of recurrence rate reported in different studies may be explained by the composition of patients with different disease severity in each study and different treatments received. Note that the major strength of this study was the analysis of the long-term recurrence rate pattern for a large population over 15 years of follow-up, and we included subjects ranging from FIGO stage la to stage IVb, based on medical records of patients admitted to the hospital during 1992 to 2005 . These findings may provide evidence for designing treatment and follow-up guidelines for patients with cervical cancer.

Our study reported several risk factors for cervical cancer recurrence, including younger age, younger age of menarche, lower parity, a greater number of miscarriages, higher clinical stage, lymph node metastasis, and treatment with chemotherapy, and all variables except parity remained significant in the multivariate adjusted Cox regression model. These risk factors identified have also been reported by previous studies. ${ }^{4,20}$ Clinical stage was the most commonly reported risk factor for cancer recurrence, ${ }^{19,21,22}$ our study results showed that patients with clinical stage II were had 1.52 times the risk of recurrence, and patients with stage III or IV had 1.84 times the risk compared to those with clinical stage I. Patients with advanced clinical stages in general have a greater range of cancer lesions, and a higher probability of peripheral invasion and lymph node metastasis, thus even if the patient was systematically treated, the possibility of recurrence for these patients was relatively higher. ${ }^{19,23}$ In this study, we observed that patients with younger age had a higher risk of recurrence. However, we also found that patients with older age were more likely to be diagnosed with cervical cancer of a higher clinical stage than those with younger age, and the majority of patients aged 55 years and above received radiotherapy instead of surgery. while it is still controversial whether age is related to recurrence with some studies reported positive associations $s^{6,24}$ and some reported negative associations ${ }^{14,25}$. It's possible that patients with younger age had better adherence to the follow-up schedule, thus were more likely to have a recorded recurrence. Unfortunately, we didn't have detailed information on the follow-up records, and it is important to further explore the reason between age and cancer recurrence. In addition, we didn't include some risk factors that has been reported in previous studies, such as smoking, age of first intercourse, HPV infection, parametrial invasion and vascular invasion ${ }^{26-28}$, and future investigations should take a more comprehensive considerations on related risk factors.

In this study, we observed that the selection of treatment plans varies by clinical stages, which jointly influenced the cancer recurrence rate. We found that surgery + radiotherapy was the main treatment plan in clinical stage I, and more than half of the patients in clinical stage II and above were mainly treated by radiotherapy alone or CRT. The selection of treatment plan in this study was in general consistent with the treatment guidelines indicating that surgery was the main treatment option for patients with early-stage cervical cancer, ${ }^{29}$ and supplemental adjuvant therapy were added based on whether the patient has a risk factor for recurrence. ${ }^{30}$ It's also important to note that this study included a heterogeneous population with large variations in clinical stages and treatment plans, and we observed that the treatment plan was not consistent with the standard guidelines for a very small number of patients. For example, a few patients in Clinical stage I and II conducted chemotherapy only without surgery or radiotherapy. On possible explanation was that these patients were not able to receive surgery due to other complications or economic reasons. It is also possible that some patients were transferred to other local hospitals

Page $13 / 21$ 
of whom the treatment regimen was not recorded in great detail. In addition, as this study collected data over a long period, we showed that the recurrence rate and survival rate increased during the follow-up period. The increase in recurrence rate may be due to the improved patient management system so that an increased number of subjects were followed up routinely and recurrence was more likely to be recorded. The improved survival rate may result from the improved standard of care over the years. ${ }^{31-34}$ Note that in recent years, cisplatin-based chemotherapy and radiotherapy for advanced cervical cancer and inoperable early cervical cancer has been widely used in clinical practice, which has been shown to improve patient prognosis. ${ }^{35,36}$

In this study, we also demonstrated the overall survival rate for subjects with and without cancer recurrence separately and showed that cancer recurrence significantly reduced the overall survival rate, especially over the long term. The five-year survival probability for patients with and without recurrence was $54.0 \%$ and $79.5 \%$, and the 10 -year survival probability was $28.7 \%$ and $63.6 \%$, respectively. Such differences in survival between patients with and without recurrence were observed in many previous studies, ${ }^{6,37}$ and these findings re-emphasized the importance of prevention of cancer recurrence in the management of cervical cancer.

Our study had several limitations. First, it was performed in patients in one hospital in South China, which may limit the ability to extrapolate these findings to the different settings. Also, the database is only available until 2010, and it would be necessary to conduct follow-up studies to update the recurrence rate data using more recent and comprehensive data records. Despite that, this study had a relatively large sample size with 5 to 19 years of follow-up, which provided a rare opportunity to study the overall trend of long-term recurrence rate for cervical cancer patients. Second, a small number of patients were lost to follow-up during the follow-up, which may lead to loss to follow-up bias, although the number has been kept to minimal as we have conducted several rounds of follow-up with multiple tracing methods. Third, despite the large overall sample size, we were not able to conduct multiple stratification analyses due to limited sample size after stratification, and we combined patients in clinical stages III and IV due to the small number of subjects in Stage IV. Fourth, we found that a very small proportion of subjects had a short disease-free time of fewer than three months after completion of the primary treatment, and these patients may have a disease progression rather than cancer relapse. However, we were not able to differentiate these patients due to limited data available.

In this study, we reported the pattern of cumulative recurrence rate using a study with 5-19 years of follow-up. The overall cumulative recurrence rate was $3.8 \%$ in the first year and increased to $8.0 \%$ in the fifth year, then the recurrence rate stayed at $9.7 \%$ in the 10 th year and $10.8 \%$ in the 15 th year. The median time to recurrence in this study was 15.5 months. Also, we reported that younger age, younger age of menarche, lower parity, a greater number of miscarriages, higher clinical stage, lymph node metastasis, and treatment with chemotherapy were significantly associated with cancer recurrence. Patients with recurrence have a much poorer prognosis in terms of survival probability compared to those without recurrence. This study may provide important evidence for designing targeted interventions for cervical cancer treatment.

\section{Material And Methods}

\section{Study Population}

Subjects for this study were recruited from a cancer specialist hospital in Hunan Province, China from January 1992 to December 2005. Subjects were recruited after they were first diagnosed with cervical cancer. The inclusion criteria were as follows: 1) subject was diagnosed with cervical cancer for the first time and had a clear 
clinicopathological diagnosis report; 2) subject had completed initial treatment in the study hospital and had a complete medical record; 3) subject was able to record the condition independently or with help to complete the follow-up activities. The exclusion criteria included: 1) subject had cognitive or communication dysfunction, or was unable to cooperate with the investigation; 2) subject had other severe diseases, including severe heart failure, renal failure, deep vein thrombosis, severe peripheral neuropathy, severe arterial insufficiency, other malignancies, etc.; 3) subject and family members did not cooperate with the recruitment process.

Informed written consent was obtained from all participants. Ethical approval was obtained from the Ethics Committee of Xiangya School of Public Health, Central South University, and all research was performed in accordance with the Declaration of Helsinki.

\section{Follow-up And Data Collection}

Baseline information was collected by trained doctors through face-to-face interviews, phone calls, and extraction of medical records. The trained doctor was responsible for filling in a questionnaire which included baseline characteristics (i.e. age, age at menarche, age of menopause, gravidity, parity, and history of miscarriage), clinicopathological characteristics (i.e. duration of discomfort before diagnosis, clinical stage, pathological type, and level of differentiation), and treatment plan (i.e. surgical method, radiotherapy method, and chemotherapy method). Clinical stage was classified according to the 2018 International Federation of Gynecology and Obstetrics (FIGO 2018) staging criteria, lymph node metastasis was classified into Yes or No based on postoperative pathological biopsy results. The pathological type and degree of differentiation were obtained according to the pathological examination report. Treatment plan referred to the treatment received after the first diagnosis, which was classified into the following categories: surgery only, surgery + radiotherapy, surgery + chemotherapy, surgery + concurrent chemotherapy and radiotherapy (CRT), radiotherapy only, CRT, and chemotherapy only. The treatment plan was decided by the physician-in-charge according to the standard treatment guidelines based on the patient's condition and willingness for treatment. The post-treatment follow-up for subjects was planned for every three to six months during the first five years, and once a year afterward

according to treatment guidelines in China. ${ }^{38}$ Follow-up for subjects' recurrence in this study was conducted every year through telephone, mail, and extraction of medical records by trained researchers after the patient was discharged from the hospital until December 31, 2010. Subjects lost to follow-up were censored, and subjects completely lost to follow-up were excluded from the data analysis. Cervical cancer recurrence was defined based on clinical-pathological diagnosis results, and this study was focused on the first recurrence of cervical cancer after the first treatment.

\section{Statistical Analysis}

Descriptive statistics were used for patient characteristics and summarized as mean \pm SD or percentages. Differences in baseline characteristics and clinicopathological characteristics and treatment plan of the study participants with and without recurrent cervical cancer during follow-up were examined using student t-test or chisquare test, as appropriate. Average time to recurrence was presented with median and interquartile range (IQR) and a Log-rank test was conducted. Kaplan-Meier survival curves were used to plot the recurrence rate and survival rate after recurrence, stratified by different risk factors. Cox proportional hazard regression was used to calculate the hazard ratio (HR) and 95\% confidence intervals (95\% Cls) for cervical cancer recurrence. Univariate analyses were conducted on all baseline characteristics, clinicopathological characteristics, and treatment plan. The final 
multivariate model was selected based on the univariate analysis and biological significance. All statistical analyses were conducted using $\mathrm{R}$ version 4.0.5.

\section{Data Availability}

The datasets used and/or analyzed during the current study are available from the corresponding author upon reasonable request.

\section{Declarations}

\section{Acknowledgments}

We thank all the participants and researchers who collaborated on the execution of this project. The study was supported by National Natural Science Foundation of China (Grant number: 82003313).

\section{Author contributions}

Study design, data analysis and interpretation, manuscript writing, and final approval of the manuscript: L.J.N. Study design, data curation, investigation, manuscript editing, and final approval of the manuscript: L.G.M., L.J.Y. Study design, data curation, investigation, manuscript editing, and final approval of the manuscript: Y.S.P. Study design, manuscript editing, and final approval of the manuscript: Y.P. Study design, manuscript editing, and final approval of the manuscript: W.J. Study design, data analysis, manuscript writing, and final approval of the manuscript: L.M.Y.

\section{Competing interests}

The authors declare no competing interests.

\section{References}

1. Peirson, L., Fitzpatrick-Lewis, D., Ciliska, D. \& Warren, R. Screening for cervical cancer: a systematic review and meta-analysis. Syst Rev 2, 35, doi:10.1186/2046-4053-2-35 (2013).

2. Sung, H. et al. Global Cancer Statistics 2020: GLOBOCAN Estimates of Incidence and Mortality Worldwide for 36 Cancers in 185 Countries. CA Cancer J Clin 71, 209-249, doi:10.3322/caac.21660 (2021).

3. Siegel, R., Naishadham, D. \& Jemal, A. Cancer statistics, 2013. CA Cancer J Clin 63, 11-30, doi:10.3322/caac.21166 (2013).

4. Peiretti, M. et al. Management of recurrent cervical cancer: a review of the literature. Surg Oncol 21, e59-66, doi:10.1016/j.suronc.2011.12.008 (2012).

5. Waggoner, S. E. Cervical cancer. Lancet 361, 2217-2225, doi:10.1016/S014013778 -6 (2003).

6. Taarnhoj, G. A. et al. Risk of recurrence, prognosis, and follow-up for Danish women with cervical cancer in 20052013: A national cohort study. Cancer 124, 943-951, doi:10.1002/cncr.31165 (2018). 
7. Colturato, L. F., Signorini Filho, R. C., Fernandes, R. C., Gebrim, L. H. \& Oliani, A. H. Lymph node micrometastases in initial stage cervical cancer and tumoral recurrence. Int J Gynaecol Obstet 133, 69-75, doi:10.1016/j.ijgo.2015.08.019 (2016).

8. Lee, W. M. et al. Clinicopathologic factors for central recurrence in patients with locally advanced bulky cervical cancer. Eur J Obstet Gynecol Reprod Biol 161, 219-223, doi:10.1016/j.ejogrb.2011.12.029 (2012).

9. Chen, Y. Y., Zhu, Y. M. \& Wu, J. C. Prognosis of Early Stage Cervical Cancer According to Patterns of Recurrence. Cancer Manag Res 13, 8131-8136, doi:10.2147/Cmar.S314384 (2021).

10. Elit, L. et al. Follow-up for women after treatment for cervical cancer: A systematic review. Gynecologic Oncology 114, 528-535, doi:10.1016/j.ygyno.2009.06.001 (2009).

11. Qian, Q. et al. Analysis of treatment modalities and prognosis on microinvasive cervical cancer: a 10-year cohort study in China. J Gynecol Oncol 25, 293-300, doi:10.3802/jgo.2014.25.4.293 (2014).

12. Chai, Y. et al. Radical hysterectomy with adjuvant radiotherapy versus radical radiotherapy for FIGO stage IIB cervical cancer. BMC Cancer 14, 63, doi:10.1186/1471-2407-14-63 (2014).

13. Cao, D. Y. et al. Comparisons of vaginal and abdominal radical trachelectomy for early-stage cervical cancer: preliminary results of a multi-center research in China. Br J Cancer 109, 2778-2782, doi:10.1038/bjc.2013.656 (2013).

14. Wang, J. et al. Patient age, tumor appearance and tumor size are risk factors for early recurrence of cervical cancer. Mol Clin Onco/ 3, 363-366, doi:10.3892/mco.2014.465 (2015).

15. Shu, T. et al. Prognostic evaluation of postoperative adjuvant therapy for operable cervical cancer: 10 years' experience of National Cancer Center in China. Chin J Cancer Res 29, 510-520, doi:10.21147/j.issn.10009604.2017.06.05 (2017).

16. Cohen, P. A., Jhingran, A., Oaknin, A. \& Denny, L. Cervical cancer. Lancet 393, 169-182, doi:10.1016/S01406736(18)32470-X (2019).

17. Lin, H. H. et al. Risk factors for recurrence in patients with stage IB, IIA, and IIB cervical carcinoma after radical hysterectomy and postoperative pelvic irradiation. Obstet Gyneco/ 88, 274-279, doi:10.1016/0029-7844(96)001457 (1996).

18. Lim, S., Lee, S. H., Lee, K. B. \& Park, C. Y. The influence of number of high risk factors on clinical outcomes in patients with early-stage cervical cancer after radical hysterectomy and adjuvant chemoradiation. Obstet Gynecol Sci 59, 184-191, doi:10.5468/ogs.2016.59.3.184 (2016).

19. Wang, H. et al. Clinicopathological risk factors for recurrence after neoadjuvant chemotherapy and radical hysterectomy in cervical cancer. World J Surg Oncol 11, 301, doi:10.1186/1477-7819-11-301 (2013).

20. Murakami, I. et al. Analysis of pathological and clinical characteristics of cervical conization according to age group in Japan. Heliyon 6, e05193, doi:10.1016/j.heliyon.2020.e05193 (2020). 
21. Chan, J. K., Loizzi, V., Burger, R. A., Rutgers, J. \& Monk, B. J. Prognostic factors in neuroendocrine small cell cervical carcinoma: a multivariate analysis. Cancer 97, 568-574, doi:10.1002/cncr.11086 (2003).

22. Twu, N. F. et al. Prognostic factors and adjuvant therapy on survival in early-stage cervical adenocarcinoma/adenosquamous carcinoma after primary radical surgery: A Taiwanese Gynecologic Oncology Group (TGOG) study. Surg Oncol 25, 229-235, doi:10.1016/j.suronc.2016.05.028 (2016).

23. Rotman, M. et al. A phase III randomized trial of postoperative pelvic irradiation in Stage IB cervical carcinoma with poor prognostic features: follow-up of a gynecologic oncology group study. Int J Radiat Oncol Biol Phys 65, 169-176, doi:10.1016/j.jijrobp.2005.10.019 (2006).

24. Yang, Y. C. et al. Cervical cancer in young women in Taiwan: prognosis is independent of papillomavirus or tumor cell type. Gynecol Oncol 64, 59-63, doi:10.1006/gyno.1996.4543 (1997).

25. Li, Y. et al. Clinical outcomes observation in stage IIB-IIIB cervical cancer treated by adjuvant surgery following concurrent chemoradiotherapy. BMC Cancer 21, 442, doi:10.1186/s12885-021-08146-3 (2021).

26. Chen, L. et al. [Analysis of prognostic factors in patients with cervical squamous cell carcinoma of stage $\mathrm{lb}$ and Ila]. Zhonghua Fu Chan Ke Za Zhi 40, 239-242 (2005).

27. Ruiz, A. M. et al. Proximity of first sexual intercourse to menarche and risk of high-grade cervical disease. $J$ Infect Dis 206, 1887-1896, doi:10.1093/infdis/jis612 (2012).

28. Roset Bahmanyar, E. et al. Prevalence and risk factors for cervical HPV infection and abnormalities in young adult women at enrolment in the multinational PATRICIA trial. Gynecol Oncol 127, 440-450, doi:10.1016/j.ygyno.2012.08.033 (2012).

29. Peters, W. A. et al. Concurrent chemotherapy and pelvic radiation therapy compared with pelvic radiation therapy alone as adjuvant therapy after radical surgery in high-risk early-stage cancer of the cervix. $J$ Clin Oncol 18, 1606-1613, doi:Doi 10.1200/Jco.2000.18.8.1606 (2000).

30. Abu-Rustum, N. R. et al. NCCN Guidelines Insights: Cervical Cancer, Version 1.2020. J Natl Compr Canc Netw 18, 660-666, doi:10.6004/jnccn.2020.0027 (2020).

31. Tsikouras, P. et al. Cervical cancer: screening, diagnosis and staging. J BUON 21, 320-325 (2016).

32. Leath, C. A. \& Monk, B. J. Twenty-first century cervical cancer management: A historical perspective of the gynecologic oncology group/NRG oncology over the past twenty years. Gynecologic Oncology 150, 391-397, doi:10.1016/j.ygyno.2018.06.023 (2018).

33. Tewari, K. S. \& Monk, B. J. Recent achievements and future developments in advanced and recurrent cervical cancer: trials of the Gynecologic Oncology Group. Semin Onco/36, 170-180, doi:10.1053/j.seminoncol.2008.12.008 (2009).

34. Leath, C. A., 3rd \& Straughn, J. M., Jr. Chemotherapy for advanced and recurrent cervical carcinoma: results from cooperative group trials. Gynecol Oncol 129, 251-257, doi:10.1016/j.ygyno.2012.12.035 (2013). 
35. Rose, P. G. Combined-modality therapy of locally advanced cervical cancer. J Clin Oncol 21, 211s-217s, doi:10.1200/JC0.2003.01.222 (2003).

36. Lukka, H. \& Johnston, M. Concurrent cisplatin-based chemotherapy plus radiotherapy for cervical cancer: a meta-analysis. Clin Oncol (R Coll Radiol) 16, 160-161, doi:10.1016/j.clon.2004.01.002 (2004).

37. Qiu, J. T. et al. Outcomes and prognosis of patients with recurrent cervical cancer after radical hysterectomy. Gynecol Oncol 127, 472-477, doi:10.1016/j.ygyno.2012.08.008 (2012).

38. Tong, J. et al. Short-term recurrence and distant metastasis following robotic-assisted radical hysterectomy with pelvic lymphadenectomy and chemoradiotherapy for a stage IB1 cervical adenocarcinoma: A case report and literature review. Medicine (Baltimore) 98, e15387, doi:10.1097/MD.00000000000 15387 (2019).

\section{Figures}




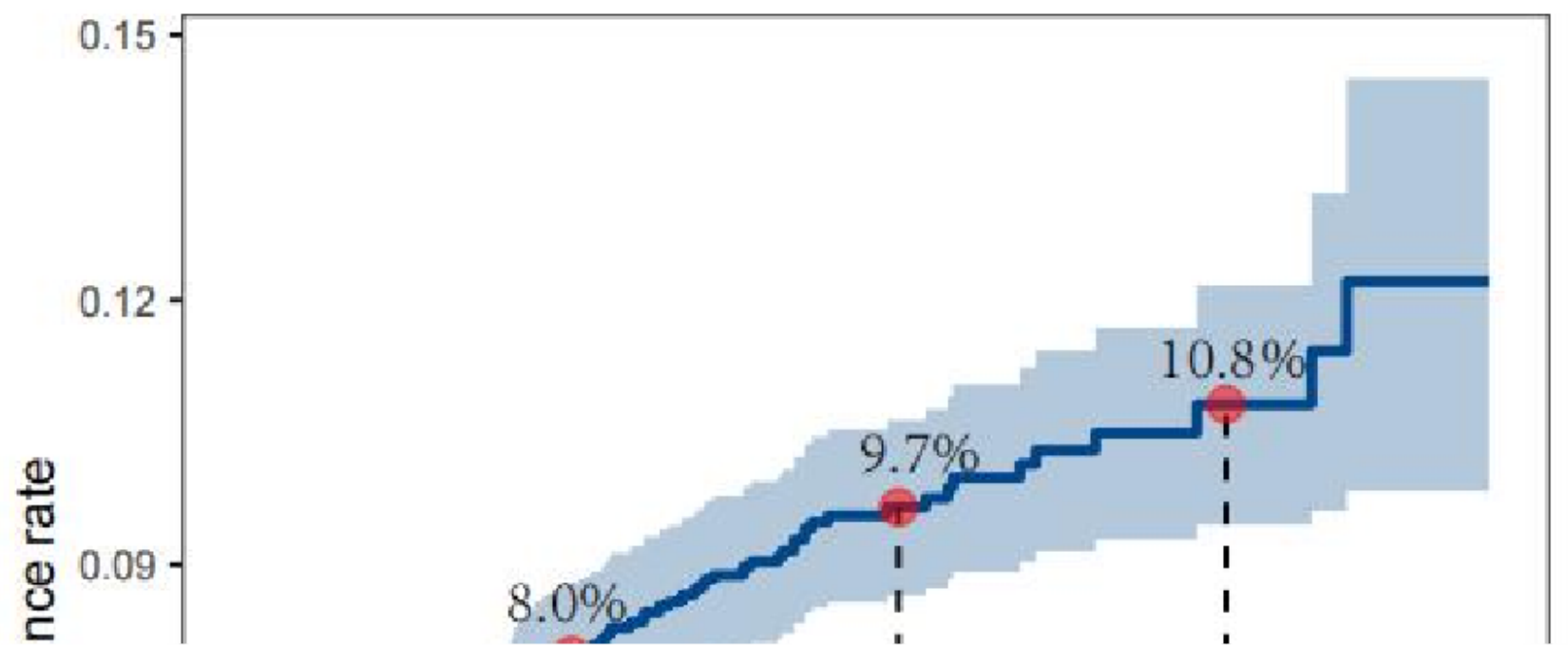

Figure 1

The overall cumulative recurrence rate

Figure 2

Cumulative recurrence rate by A. Age group; B. Age of menarche; C. Parity; D. Miscarriage; E. Clinical stage; F. Treatment plan; G. Lymph node metastasis; H. Chemotherapy 


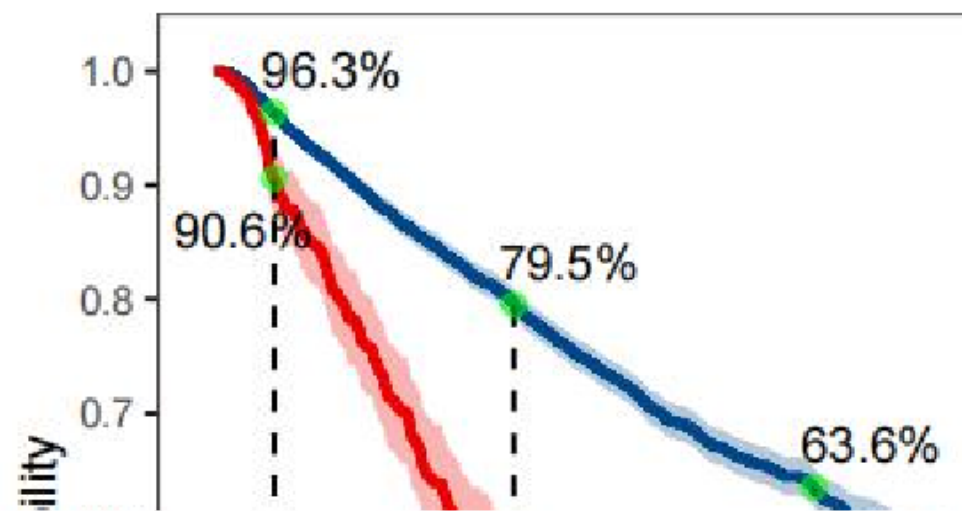

Figure 3

The overall survival probability by recurrence

\section{Supplementary Files}

This is a list of supplementary files associated with this preprint. Click to download.

- SupplementalTables.docx 